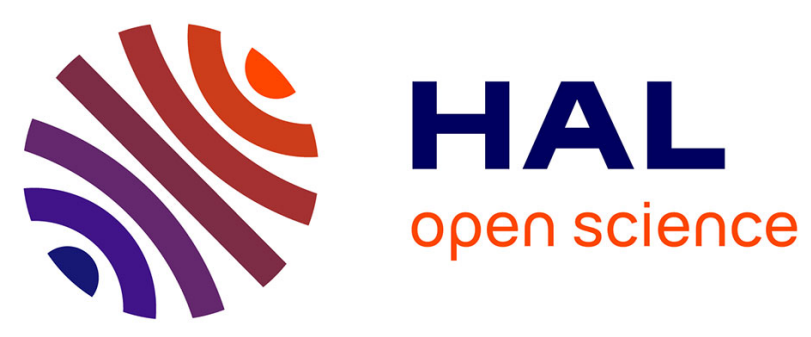

\title{
Infra-red imaging and EL2
}

\author{
J.P. Fillard
}

\section{To cite this version:}

J.P. Fillard. Infra-red imaging and EL2. Revue de Physique Appliquée, 1988, 23 (5), pp.765-777. 10.1051/rphysap:01988002305076500 . jpa-00245881

\section{HAL Id: jpa-00245881 https://hal.science/jpa-00245881}

Submitted on 1 Jan 1988

HAL is a multi-disciplinary open access archive for the deposit and dissemination of scientific research documents, whether they are published or not. The documents may come from teaching and research institutions in France or abroad, or from public or private research centers.
L'archive ouverte pluridisciplinaire HAL, est destinée au dépôt et à la diffusion de documents scientifiques de niveau recherche, publiés ou non, émanant des établissements d'enseignement et de recherche français ou étrangers, des laboratoires publics ou privés. 
Classification

Physics Abstracts

$42.30-61.70 \mathrm{~J}-81.70-85.40$

\title{
Infra-red imaging and EL2
}

\author{
J. P. Fillard \\ LINCS, Centre d'Electronique de Montpellier, USTL, Place E. Bataillon, 34060 Montpellier, France
}

(Reçu le 15 juillet 1987, révisé le 9 octobre 1987, accepté le 11 février 1988)

\begin{abstract}
Résumé. - On indique d'abord les caractéristiques spectroscopiques d'EL2 qui permettent d'identifier le défaut dans GaAs semi-isolant (s-i). On passe en revue les méthodes de cartographie optique de distribution macroscopique des défauts dans GaAs.s-i. Les images par transmission révèlent une distribution inhomogène de $E L 2^{\circ}$, qui paraît anticorrélée avec la distribution de $E L 2^{+}$. On montre que la diffusion de la lumière pourrait expliquer la structure en cellule également observée dans les images par transmission. Ces structures sont étudiées plus commodément en tomographie par diffusion laser (TDL), qui permet une meilleure résolution spatiale. Le contraste observé est discuté en fonction de l'origine des tranches et des recuits thermiques. La variation du contraste en TDL avant et après phototrempe de EL2 ${ }^{\circ}$, qui permet de corréler directement les centres diffusant et EL2, est encore un point controversé dont l'issue peut être établie par imagerie à basse température. Il existe une relation entre l'intensité des images en photo-cathodoluminescence et la distribution des dislocations dans les tranches, mais il demeure à expliquer le rôle des dislocations dans la présence ou l'absence des défauts EL2.
\end{abstract}

\begin{abstract}
After a presentation of the spectroscopic features used to identify EL2 defect in semi-insulating GaAs, a critical review of the methods which can give an optical mapping of the macroscopic distribution of defects in GaAs is presented. The transmission images reveal an inhomogeneous distribution of EL2 ${ }^{\circ}$, which seems to be anti-correlated with the distribution of EL2 ${ }^{+}$. The optical mechanism responsible for the cell structure also observed in the image could be scattering. This is more conveniently studied using laser scattering tomography (LST) which allows a better spatial resolution. The texture observed by LST is discussed as a function of the origin of the wafer studied and of their thermal annealing. The result of studies of the change in the LST images before and after photo-quenching of EL2, which could help to make a correlation between scattering centers and EL2 is still controversial. On the other hand, there is a clear relation between the photo-cathodo-luminescence images intensity and the distribution of dislocations in the wafer, but the point remains to explain the role of dislocations in the occurrence of EL2.
\end{abstract}

\section{Introduction.}

Experimental investigations on classical semiconductors (resistivity, Hall effect, optical absorption, electron paramagnetic resonance, etc.) usually refer to a macroscopic appraisal of the homogeneous material ; the deduced parameters (mobility, densities of carriers, capture cross sections, etc.) are considered as quantitative, meaningful values for the bulk material.

Such a situation does not hold in the case of GaAs-like materials, even if carefully prepared: they include large macroscopic and microscopic fluctuations of the composition (entangled dislocations, impurity or excess species clusters) which induce large local variations of the parameters.

Therefore any relevant evaluation of the quality of the material requires a spatial description i.e. a $2 \mathrm{D}$ or even a 3D image or mapping. Such spatial disorder will certainly correlate with the dispersion of the specifications (such as Vth) of individual FETs or OEICs. The exact grounds of this correlation are not yet clearly established, nevertheless, concerning $\mathrm{GaAs}$, a prominent role is to be assigned to the $E L 2$ family of defects because of its participation in many electrical or optical mechanisms.

Conferences were especially devoted to this problem of Defect Recognition and Image processing [1, 2]. They were held in Montpellier (DRIP I 1985) and Monterey (DRIP II 1987).

The exact nature of EL2 centres is still a matter of controversy and details will be found in other chapters; in brief it may likely include an antisite $\mathrm{As}_{\mathrm{Ga}}$ possibly associated with other kinds of defects such as $\mathrm{V}_{\mathrm{As}}, A s_{\mathrm{i}}$, chemical donors or acceptors $[3,5]$ 
giving rise to a series of closely similar defects $[6,7]$. The role of thermal stresses and dislocations in the generation or the gettering of EL2 is a matter of non conclusive discussions $[8,9]$ especially with the advent, some years ago, of dislocation free (DF) Indium doped materials [10] : this semi-insulating material actually contains [11] comparable EL2 densities (within a factor 2 or 3 ) to the one found in standard crystals. Also the modifications in the EL2 density distributions must be considered as a consequence of the physical processes introduced during the fabrication of devices (implantation, annealing, etc.).

Several methods of imaging were tentatively used which proceed from interaction of the material with infra-red light: absorption, scattering and luminescence. They revealed a macroscopic distribution of the defect in agreement with data obtained using etch pit density (EPD) measurements, resistivity mapping. Hall mobility or even EPR techniques. Nevertheless it is not easy to find a definitive finger print or signature unambiguously related to EL2 sites. May be the most convenient one to date relies on the low temperature photo-quenching (PQ) mechanism which converts the centre into its passive metastable state [12]; in such a case the revealed centres are only those which have an electron in the fundamental state $\left(\mathrm{EL} 2^{\circ}\right)$ : ionized $\mathrm{EL} 2^{+}$as well as metastable $\mathrm{EL} 2_{\mathrm{m}}$ are not affected by $\mathrm{PQ}$.

In this paper we will present the state of the art in the investigation of EL2 centres by techniques of infra-red imaging: infra-red Transmission (IRT), Laser Scanning Tomography (LST) and Cathodo/Photoluminescence (C/PL). A discussion on the results will conclude this body of experimental data.

\section{Infra-red transmission images.}

2.1 EL2 INFRA-RED IDENTIFICATION. - Original identification of EL2 centres was obtained from photocapacitance experiments [13] with a signature slope in the range of $0.75-0.8 \mathrm{eV}$ and even if this energy was later shown to be more diversified $[6,14]$ it was clear enough to associate this capacitance measurement with the typical photo-quenching phenomenon $[15,16]$. Unfortunately DLTS is not easy to handle and the signal can depend on the nature of the Schottky contact [17]; it cannot generally be used on semi-insulating materials and the spatial resolution is not very good. It was soon preferred to control EL2 concentration with infrared transmission measurements [18] in the range of $1.15 \mu \mathrm{m}$ wavelength : these measurements being converted into an absorption coefficient $\alpha\left(\mathrm{cm}^{-1}\right)$. The wary experimentalist has to be very careful in interpreting these results as there are other competitive optical contributions due to multiple reflections, surface faults or internal scattering, coherence and phase interactions which are ignored in most papers covering the subject.

This calibration method initially proposed by Martin [18] relates the absorption coefficient to the density of unquenched EL2 in the neutral state (usually $10^{15}-10^{16} \mathrm{~cm}^{-3}$ ). This calibration obviously requires an exact evaluation of the optical cross section $\sigma_{n}$ which is deduced from optical DLTS experiments [16]. Similar efforts were also performed on photoluminescence emission at $1.55 \mu \mathrm{m}$. It has to be noted, however, that Tajima [19] cast some doubt on the exact correspondence between DLTS and IRT or C/PL calibrations because some samples show very inconsistent profiles.

Even though this procedure was largely used and afterwards improved by introducing adjustments taking into account :

- the occupancy of the fundamental level [20] evaluated from the Fermi function

- the competitive transitions [21] from the valence band $\left(\sigma_{\mathrm{p}}\right)$

- the spurious effects of absorption on unquenchable centres [8, 22, 1] or other kind of artefacts [23].

This latter point becomes especially important when dealing with very transparent materials such as GaAs at $1.1 \mu \mathrm{m}\left(\alpha=1 \mathrm{~cm}^{-1}\right)$. Actually a large part (up to $5 \%$ of the incident light) of the light is scattered [24] in the bulk from its initial direction by microscopic defects or extended faults $[23,25]$ or by refractive index inhomogeneities [23, 26].

Also it still remains evident that such an optical measurement corresponds to averaging over the thickness of the sample and over the cross section of the probe beam : the corresponding volume could consist of a highly inhomogeneous bulk material.

The infra-red quantum absorption associated to the EL2 complex defect includes several transitions [27] from the fundamental state towards the conduction band minima : they were identified [28] from a Zero Phonon Line (ZPL) which is probably not unique [113] ; other transitions very close to the gap are observed which could be related to EL2 through a possible chemical impurity (donor) participating in the defect structure $[3,29,30,31]$. These transitions are sensitive to the photo-quenching regeneration mechanism, they are also used to mark the EL2 centres and give rise to contrast inverted images [32, 34].

The exact nature of EL2 is not definitely established and the possible role of the anti site $\mathrm{As}_{\mathrm{Ga}}^{+}$is still a matter of debate. The exact role of grown-in or strain induced dislocations in the generation or in the gettering process has also to be explained [3, 7 , $8,36,37,35]$. These points will be emphazised through the analysis of transmission or tomography or luminescence images. 
2.2 TRANSMISSION IMAgE ANALYSIS. - For a long time images were used to account for the distribution of dislocations in semiconductors : the two essential techniques were Nomarski contrast photography of etched surfaces (EPD measurements) and $X$ ray transmission or reflection Topography (XRT). The density of dislocations was considered as a test of quality of the material.

The first IRT macroscale images were proposed by Brozel in 1983 : they gave evidence of a large and structured disorder in the material. An example [32] is given in figure 1.

The experimental set up used in IRT are somewhat diversified : photographic film [39], infra-red vidicon [38], extended infra-red vidicon [40], silicon diode array [41] or even scanning single detector [42]. They all bring specific advantages and drawbacks but give similar images of the internal structures of defects.

Wafers from standard Liquid Encapsulated Czochralski (LEC) grown undoped crystals (Fig. 1) shows in the central zone a network of clear cells (200-500 $\mu \mathrm{m}$ wide) limited by dark blurred walls ; in the peripheral region these cells are disturbed and also appear streamers and lineages which are oriented along $\langle 110\rangle$ directions as rectangular cross. This dense pattern is superposed over a grey background which often shows a fourfold figure of clearer zones centered on the $\langle 110\rangle$ directions as shown in figure 2. These zones also correspond to regions of lower EPD.

2.2.1 Fourfold background. - This macroscale figure corresponds to a $\mathrm{W}$ diametral profile of absorp-

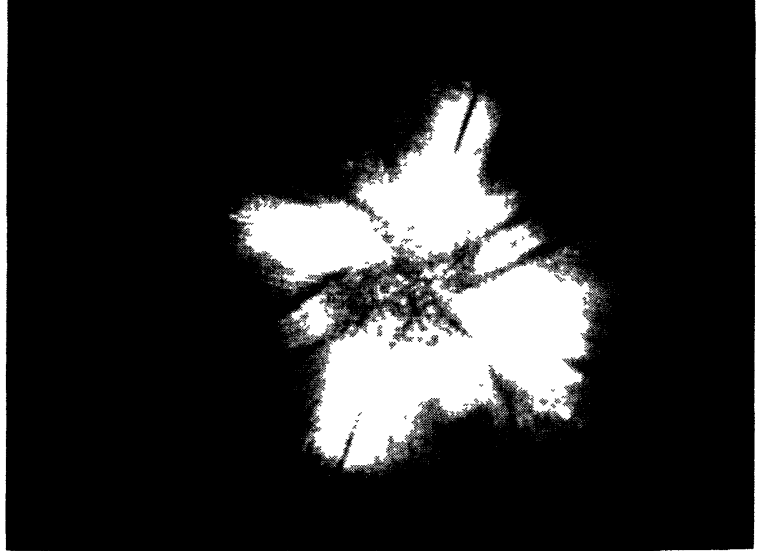

a)

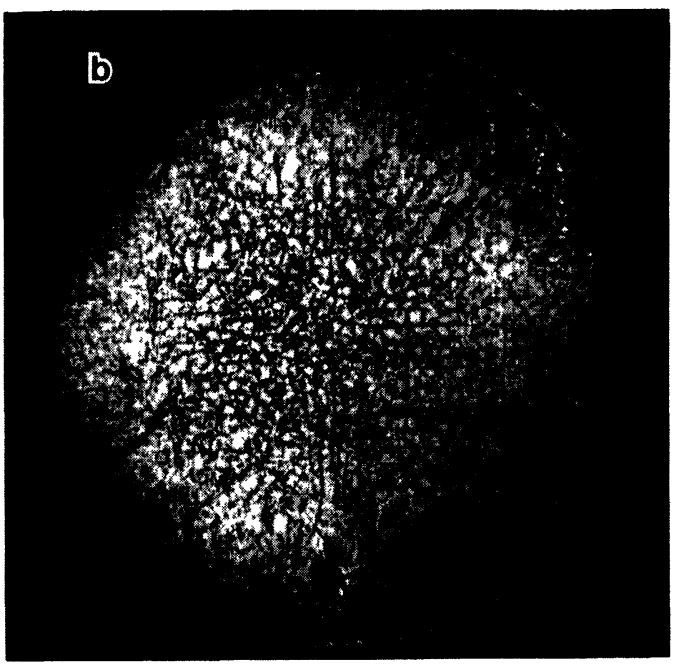

Fig. 2. - a) IRT wafer scale image showing the four fold symetry of clear zone. b) Surface etching wafer scale image (after M. P. Scott).

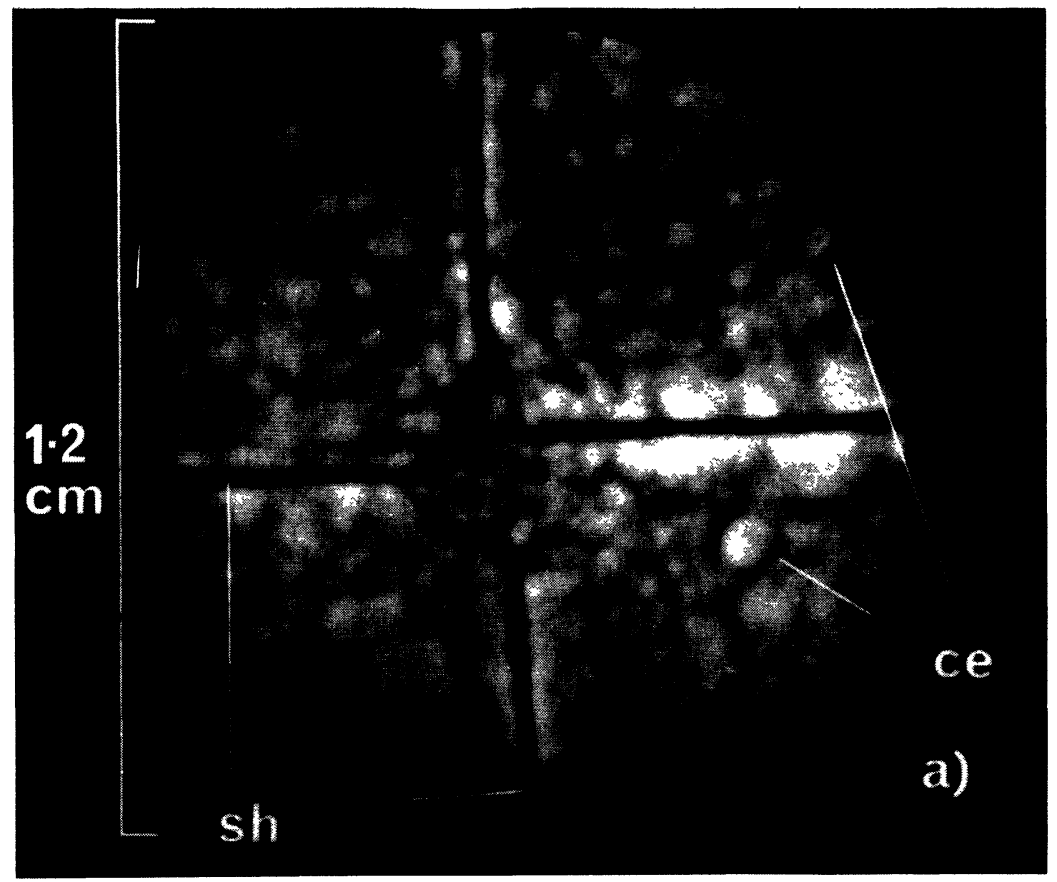

Fig. 1. - IRT typical image showing the cell structure (CE) and lineages (sh) (after M. S. Skolnick). 


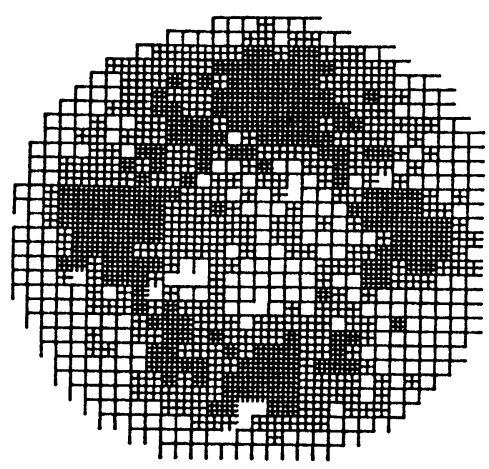

Valeur moyenne $=5,73 \cdot 10^{3} \quad \Omega \mathrm{cm}$ Ecart-type $=1,84 \cdot 10^{3} \Omega \mathrm{cm}$ de $2,00 \cdot 10^{3}$ à $5,00 \cdot 10^{3} \Omega \mathrm{cm}$ de $5,00 \cdot 10^{3}$ à $7,00 \cdot 10^{3} \Omega \mathrm{cm}$ de $7,00 \cdot 10^{3}$ à $1,20 \cdot 10^{3} \Omega \mathrm{cm}$

Résistivité

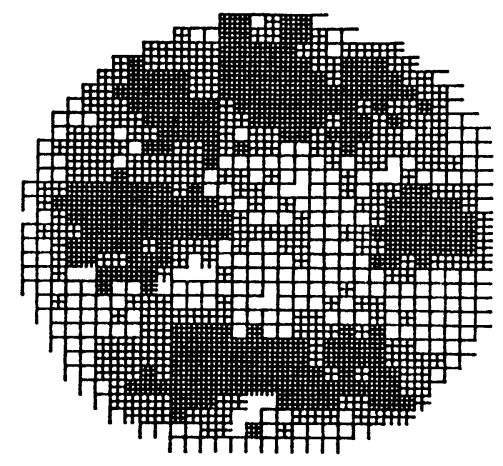

Valeur moyenne $=1,21 \cdot 10^{7} \mathrm{~cm}^{3} / \mathrm{Cb}_{1}$ Ecart-type $=4,15.10^{6} \mathrm{~cm}^{3} / \mathrm{Cb}$ de $4,00.10^{6}$ à $1,00.10^{7} \mathrm{~cm}^{3} / \mathrm{Cb}$ de $1,00 \cdot 10^{7}$ à $1,40 \cdot 10^{7} \mathrm{~cm}^{3} / \mathrm{Cb}$ de $1,40.10^{7}$ à $2,40 \cdot 10^{7} \mathrm{~cm}^{3} / \mathrm{Cb}$

Mobilité de Hall.

Fig. 3. - Resistivity and Hall mobility map (after M. Bonnet).

tion; it is undoubtedly related to the electrical properties [43] as sketched in figure 3 and refers to the local density of neutral EL2 centres controling the position of the Fermi level [44].

This $\mathrm{W}$ profile is usually observed in the top end of the ingot and progressively changes into a $\mathrm{U}$ shape (ring distribution) in the tail [43]. This fourfold symmetry [45] was predicted by the quasi-static transfer model proposed by Jordan [46] : the radial distribution of the EL2 centres should be composed of a uniform contribution directly related to the stoichiometry and a second variable mechanism giving a spatial modulation (Fig. 4) as proposed by Holmes [47]. This latter contribution is enhanced by local As excess which favors [37] the EL2 creation : $\mathrm{As}_{\mathrm{Ga}^{+}} \mathrm{As}_{\mathrm{i}} \rightarrow$ EL2. Experiments on Magnetic Circular Dichroïsm carried out by Spaeth [48] seems to indicate that $\mathrm{EL} 2^{\circ}$ and $\mathrm{EL2}{ }^{+}$distributions should be

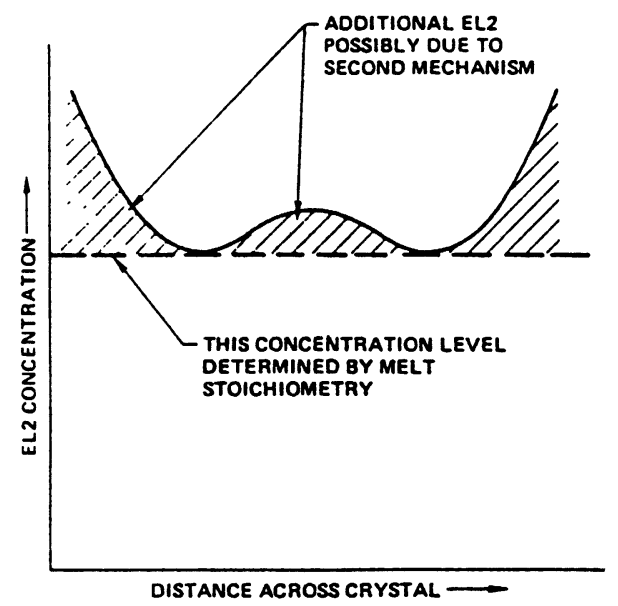

Fig. 4. - Diametral distribution of EL2 as proposed by D. E. Holmes. anti correlated thus leading to a uniform EL2 density. Other interpretations of this $\mathrm{W}$ distribution of EL2 ${ }^{\circ}$ suppose that it is the result of a variation of compensation due to acceptors [49].

Materials grown under low pressure conditions or Vertical Gradient Freeze (VGF) are less sensitive to this modulation. In doped materials as well as Bridgman grown materials do not exhibit such properties even though Blakemore discovered faint fourfold structures in In- doped samples [20].

This background was attributed to the EL2 ${ }^{\circ}$ microscopic defect because it contributes significantly to the absorption coefficient but essentially because it is very sensitive $[34,35]$ to the $P Q$ induced at $77 \mathrm{~K}$ : after an illumination with white light the background of transmitted light increases and the fourfold structure vanishes. Thermal regeneration [20] of the PQ induced changes occurs for temperatures above $125 \mathrm{~K}$ as expected for $\mathrm{EL} 2_{\mathrm{m}}$ centers [30]. Similar behaviour is also noted in In-doped or Bridgman grown materials because they are known to contain similar densities of EL2 ${ }^{\circ}$ centers, independently of the dislocations. Nevertheless the PQ effect is lower, leading to the opinion that these centres are less numerous [33].

Concerning high temperature annealing it is known that the electrical resistivity and the related EL2 density become more homogeneous [52]; it is confirmed in the IRT macroscale images that the fourfold clear zones disappear [53] whereas absorption reaches a saturation value $[54,55]$ corresponding to an EL2 concentration of $2 \times 10^{16} \mathrm{~cm}^{-3}$; this is reported [56] in figure 5.

2.2.2. Cell pattern. - Originally the cell network was discovered [38] in thick samples $(6 \mathrm{~mm})$ and the resulting contrast was faint ; this strongly limits the spatial resolution independently of the camera lens 


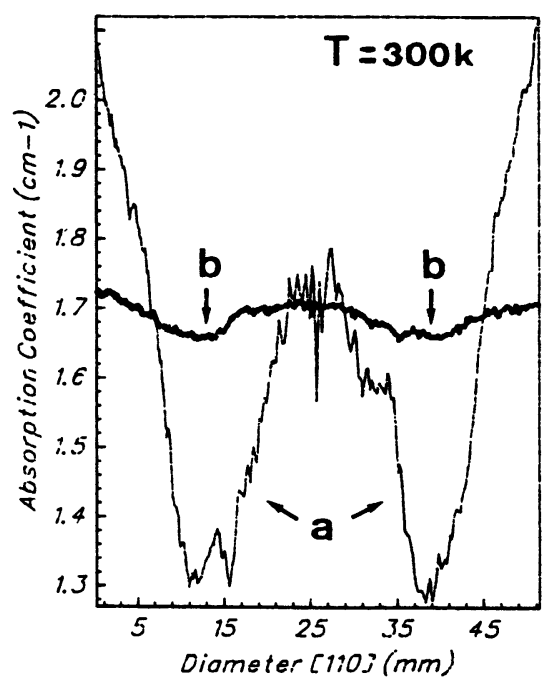

Fig. 5. - Wafer scale diametral profile (a) before and (b) after annealing. (after E. Molva).

specifications [57]. The physical objects which constitute the walls of the cells cannot be resolved individually and the observed image result from an integration of these objects over the thickness of the sample; the image is more relevant to a cloud of objects than to the objects themselves [58]. Nevertheless stereo images of the cells were obtained [59] which were interpreted as revealing a columnar organization of cells. Comparison of IRT with XRT and etch pit images [41] satisfactorily confirmed that the dark walls correspond to regions of high density of entangled dislocations.

Improving the contrast specifications of the image detection is the key to obtain higher resolution and to understand the exact origin of the IRT topographs. This aspect has been especially developed in dedicated systems such as SATTIR [60] or IRTS II [65]. Classical images display a contrast much larger than $30 \%$ whereas IRT images are [61] in a range below $1 \%$. These special systems also have to remove specific low contrast image perturbations such as vignetting (i.e. a circular shadow on the border of the optical field). Such contrast enhancement allows resolved filaments to be observed in the cell walls in standard wafers $500 \mu \mathrm{m}$ thick. In figure 6a-b are shown two photographs and respective intensity profiles for a thin (a) and a thick (b) sample; the overmodulation phenomenon due to thickness integration is clearly observable (Fig. 6b).

From the first investigations on these IRT images it was proposed that the walls of the cell were characterized by a larger local density of EL2 ${ }^{\circ}$ and a resulting larger absorption coefficient. Stirland [62] suggested that the microenvironnement of the dislocations would be richer in EL2 centres than the inner part of the cell. This point of view was largely accepted [37, 44, 63, 64, 65] in spite of arguments

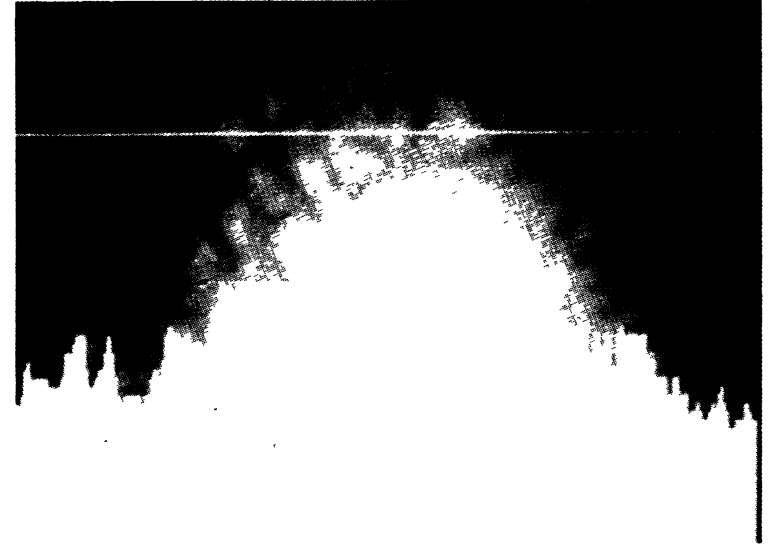

a)

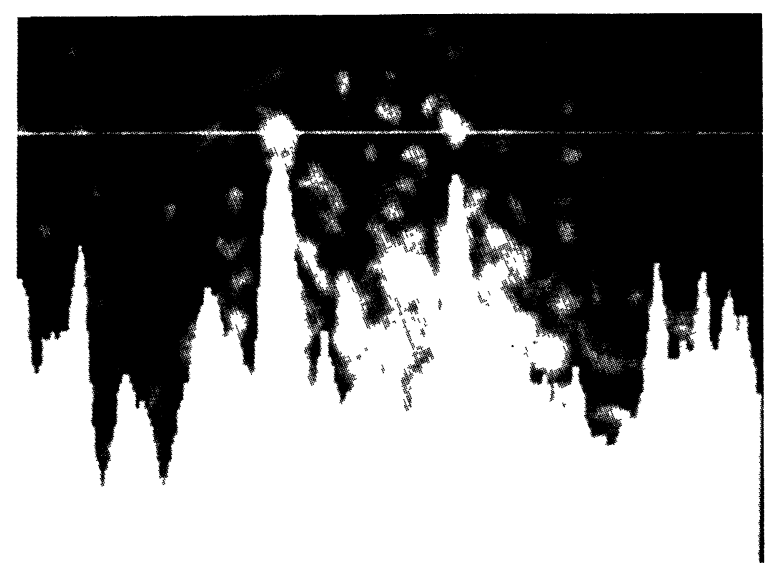

b)

Fig. 6. - IRT images and profiles corresponding to a thin sample (a) and a thick one (b). The statistical effect of cell stacking is clearly observed on the profile (b). (after Wang Li).

based on the relative importance of the scattered light [23]. Then the point is the understanding of the mechanism of EL2 generation or gettering by dislocations [66]. Alternative models were also proposed by Bray [36] and Weber [7] using the balanced equilibrium with an acceptor. No satisfying answer can be given and Blakemore [64] has even found that the correlation of $\mathrm{EL}^{\circ}$ with dislocations is not observed everywhere.

The electrical specifications of the FET structures depends on the proximity of the closest dislocation [67] and some doubt has even been cast on such a direct correlation [68] Blakemore [20] considered that the relation could be provided through the EL2 centre more likely than through the dislocation itself. Obviously it is established that the micro environment of a dislocation is strongly affected [69].

Among the main arguments supporting this EL2 cladding of the dislocations was the observation of the low temperature photo-quenching: Skolnick 


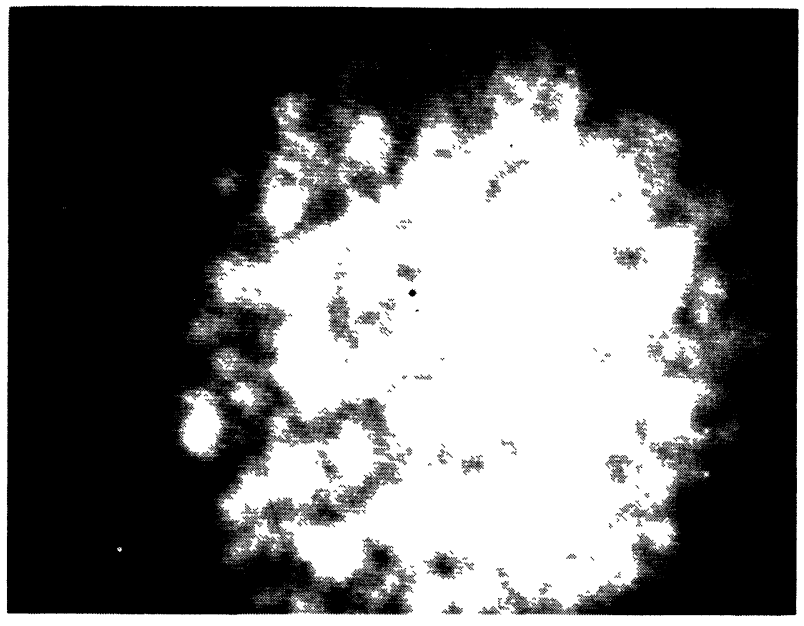

a)

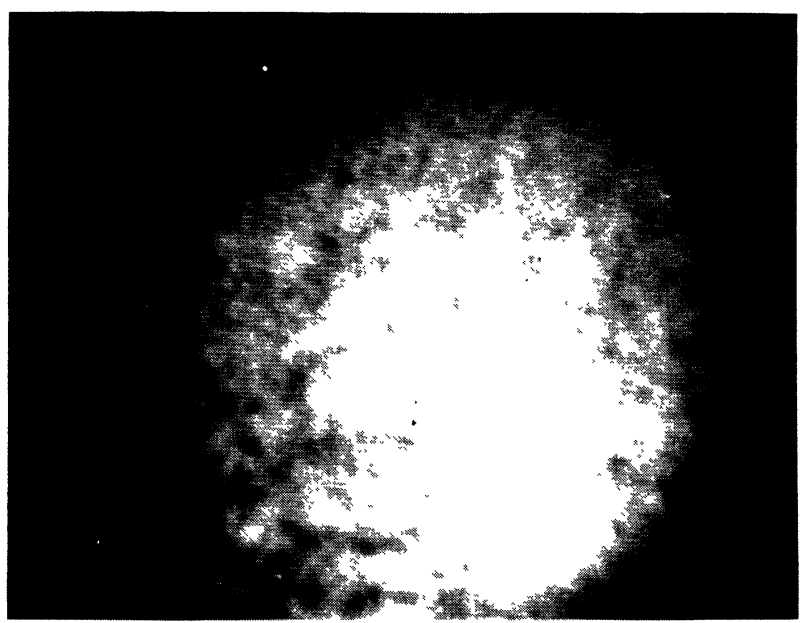

b)

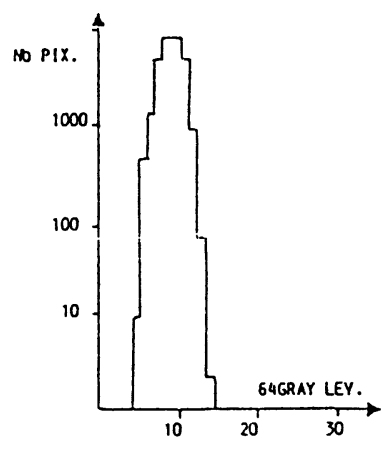

c)

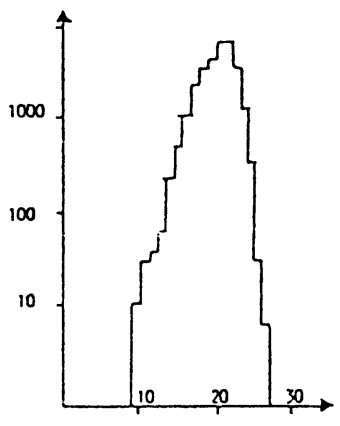

d)
Fig. 7. - IRT image of a thick sample before (a) and after (b) quenching with corresponding histogrammes (c-d). (after J. P. Fillard).

and others observed [70, 40] that the pattern disappear at $30 \mathrm{~K}$ after $\mathrm{PQ}$ at the same time the background is bleached, thus demonstrating the strong involvment of EL2 in the pattern definition. Subsequently, experiments performed by Fillard $[34,35]$ clearly demonstrate by image quantitative analysis (using the very samples used by Skolnick) that $\mathrm{PQ}$ at $77 \mathrm{~K}$ does not affect the image pattern but only the background intensity. This seems to be an evidence that the usual EL2 species which quenches below $125 \mathrm{~K}$ are not concentrated [43] on dislocations but rather uniformly distributed in the bulk. A definitive answer will be provided by very low $(T=4 \mathrm{~K})$ temperature $\mathrm{PQ}$ experiments because it is known that some EL2 species [3, 30, 71] could regenerate at $T=50-60 \mathrm{~K}$.

So, if quantum absorption on EL2 sites is not the main origin of the image of the network then we must take into consideration the large scattering of photons [23] which occurs on the decorated dislocations and gives rise to the LST images [72]. The IRT image contrast could simply be due to the scattered and lost photons ; this is consistent with the high refractive index of GaAs $(n=3.5)$ and the focussing requirement $[23,59]$ which does not hold in the case of absorption (shadow casting).

Another interesting discussion in the field was proposed by Dobrilla [66] ; supposing that EL2 is generated in the close vicinity of dislocations, the high EL2 density regions would correspond to small cell regions (high EPD) whereas if EL2 is generated independently from dislocations the cell modulation would be superimposed on a background evolution. The situation is depicted in figure 8 . It was observed that the two models were partially satisfied in such way that the microstructure should be due to gettering (enhanced by As excess) and that macrostructure (background) should be related to a growth mechanism. This point is not conflicting with our own conclusions.

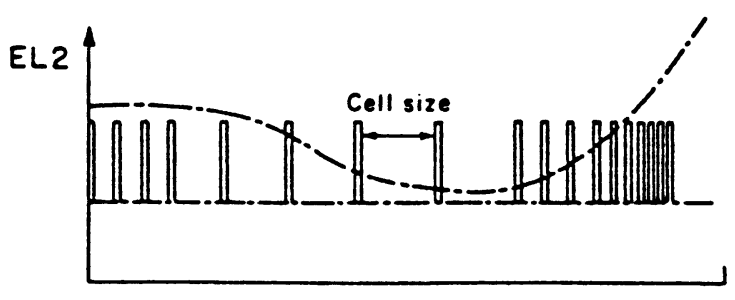

a)

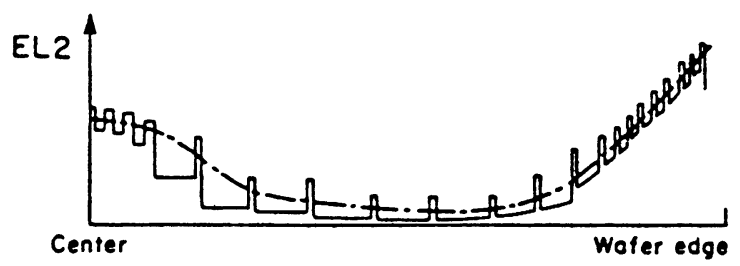

b)

Fig. 8. - Cell size evolution and background evolution; model poposed by P. Dobrilla.

After annealing of the wafer, the IRT image pattern is weakly affected and the grown-in dislocations are stable [55] although EL2 migrates over large distances as deduced from the vanishing $\mathrm{W}$ 
profile. So it could be possible that the electrical influence of the dislocations [52, 72, 73] could be attributed to chemical impurities or to excess Arsenic rather than to EL2 itself. The role of the undecorated dislocations induced by plastic deformation in the IRT images must be carefully examined: it is established that the quenchable EL2 density does not change even if $10^{8} \mathrm{~cm}^{-2}$ fresh dislocations are introduced.

As a conclusion, from this IRT analysis, it could be proposed that EL2 is a microscopic defect rather uniformly distributed in the bulk of the material, without any special correlation to the dislocations. The occurrence of the image contrast optimization for a wavelength at $1.1 \mu \mathrm{m}$ in the same range as the discrete absorption of EL2 should result from an indirect relation and it was shown by Ogawa [25] that the scattering also is maximum at the same wavelength. So the question to answer now is what could be the physical mechanism of the scattering of the infra-red light.

Another point to take into consideration is the behaviour of the images in the range of the high absorption close $(50 \mathrm{meV})$ to the gap. It was observed that this region is sensitive $[29,30]$ to $P Q$ (then related to EL2) which gives rise to an inverted contrast image (Fig. 9) of the cell pattern [74]. But

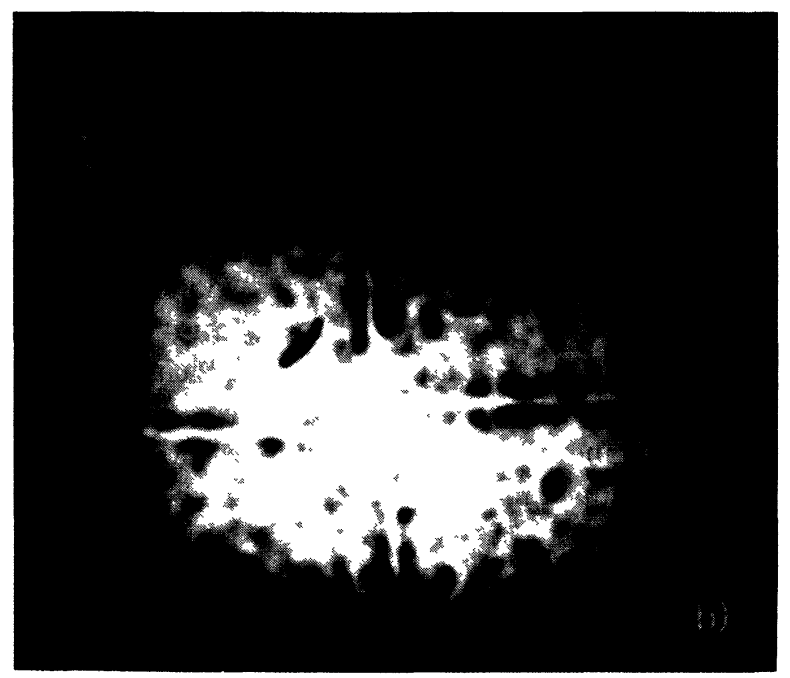

Fig. 9. - Band gap inverted transmission image at $T=10 \mathrm{~K}$ (after Skolnick).

further investigations $[33,34]$ showed that the inverted image still exists before quenching. Many shallow traps were identified in this energy range [75] which are related to EL2 [5] ; the stability of this image with respect to $P Q$ leads to the opinion that it belongs to an absorption mechanism independent of EL2 or to a coherence artefact of diffracted photons or also to an effect of local gradient in the refractive index [26].

\section{Laser scattering tomography.}

The very low value of the aptical absorption for wavelengths greater than $1 \mu \mathrm{m}$ and the high refractive index of GaAs make it possible to inject a thin parallel laser beam into GaAs wafers and to observe the light scattered by imperfections along the path of the beam. A video camera is placed at $90^{\circ}$ from the beam direction to record the linear image of the illuminated sample through the polished plane face of the wafer. Then a complete two dimensional image can be constructed by a computer after after step by step scanning of the whole sample by the laser beam. Experimental details and results will be found in the literature (1) $[25,57,75,77]$; this special technique is now considered as standard [73, 78].

The image refers to a virtual plane of tomography the thickness of which corresponds to the diameter of the illumination beam of course the contrast is very bright because of the dark background; the spatial resolution is limited only by diffraction but objects below this limit can be detected as long as they behave as efficient scatterers (ultra-microscopy).

Many of the difficulties and drawbacks encountered in IRT are removed with LST and the computer even allows the gathering of sufficient data from successive parallel planes to reconstruct a 3D description of the bulk material. This LST operation is non destructive and can be performed at room temperature without any special precautions except for the need to have a flat cross section to inject the beam into the crystal and a polished viewing surface.

Highly detailed images have been obtained by this technique, which confirm the observation by Castagné of an important scattering yield in the bulk of GaAs ; this phenomenon clearly belongs to a Rayleigh [25, 75] mechanism ; Katsumata [65] showed that the wavelength of the scattered light was exactly the same as that of the laser beam thus eliminating the possibility of a luminescence contribution. Ogawa [25] also discovered that the scattering yield was resonant for the EL2 fundamental transition at $1.1 \mu \mathrm{m}$. Qualitatively the LST images agree with XRT or IRT observations : dealing with usual LEC undoped materials a similar pattern of cells can be observed (Fig. 10). Nevertheless it is to be kept in mind that IRT makes an integration of the pattern over a much larger thickness of material; the LST plane thickness corresponds to the entering laser spot (i.e. some ten microns).

The LST image is more detailed than the IRT image as can be seen in figure 11 ; the tomographic construction for instance revealed that the dark central cross often observed in GaAs wafers is not made of thick bulky walls but only of a thin plane made up of threading dislocations and whose orien- 


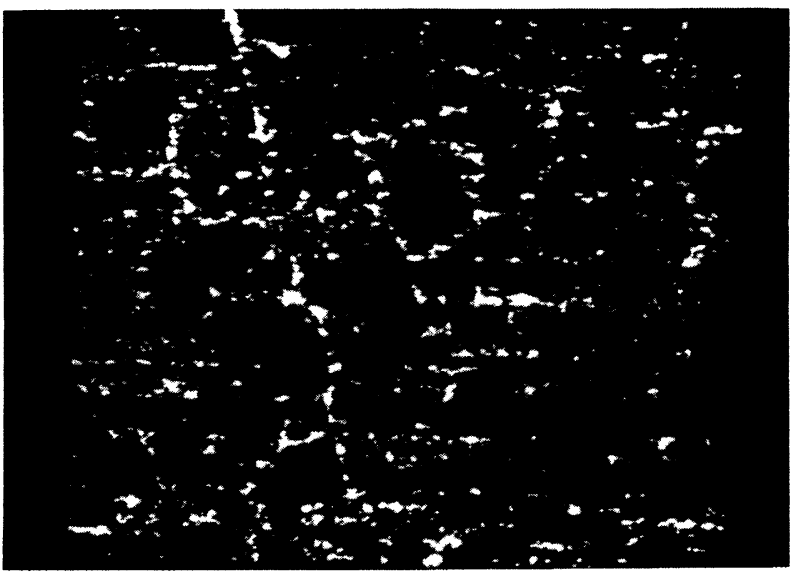

Fig. 10. - Laser Scanning Tomography of scattered light from a classical LEC undoped GaAs material: cell contours can be clearly observed. (after J. P. Fillard).

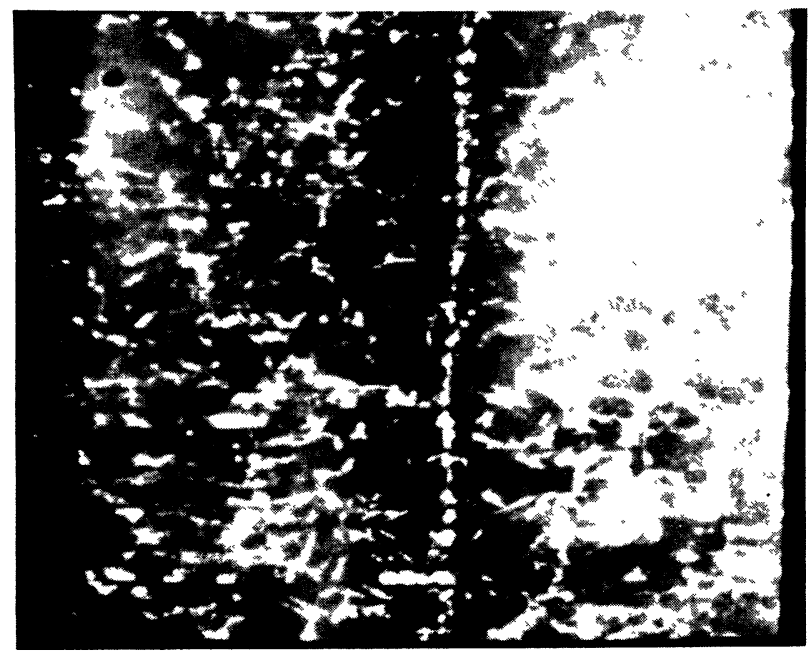

Fig. 11. - LST and IRT superposed images. The vertical dark shadow corresponds to a lineage ; interception by the LST plane (bright features) is linear thus demonstrating that the lineage is a flat plane of dislocation slighted tilted with respect to the growth axis $\langle 001\rangle$ perpendicular to the photo. (after J. P. Fillard).

tation makes a small angle with the growth axis. LST images also revealed that the cell walls are not homogeneous but look rather like having a spongy texture as that observed on etched surfaces [69].

The individual point scatterers are related to dislocations intercepted by the tomographic plane and it is worth noting [79] that they are statistically arranged [57, 61] along crystallographic directions $\langle 110\rangle$ and $\langle 100\rangle$. Varying the nature of the material gives LST images consistent with previous IRT observations ; for instance lightly doped GaAs : In is depicted in figure 12 . Nevertheless Ogawa observed that LST reveals a special kind of dislocation which is not observed on the IRT images.

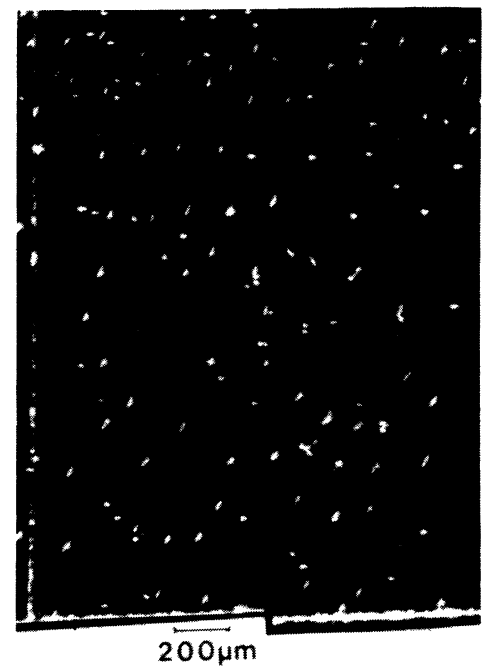

Fig. 12. - LST image from an indium doped LEC sample. (after J. P. Fillard).

The texture of the cell pattern greatly changes with the material, the doping, the position in the wafer or in the ingot [77] : the central zone of cells generally observed at the seed end progressively extends to the total wafer in the tail region and at the same time the cells become larger. This observation is consistent with the previous profiles of EL2 changing from a W shape to a $U$ shape [43]. At the same time, it is also noted that LST intensity decreases and it is not clear if this is due to a decrease in the density of scatterers or in their yield.

With In-doped materials $(\mathrm{In}>1 \%)$ the cell structure observed in IRT, LST, as well as XRT disappears ; the only features in the corresponding images are related to individual dislocations (mainly oriented $\langle 001\rangle$ ), clouds of micro-precipitates and also striations of indium doping. The background absorption mentioned in IRT images does not give rise to any background scattering which means that EL2 must not be considered as a microscopic scatterer. In undoped materials it was shown by Katsumata [65] that low As materials or materials grown in a magnetic field display a faint LST structure whereas the IRT image is still valid. The LST intensity roughly varies as the fourth power of the absorption coefficient $\alpha$ thus indicating a possible different origin of the IRT and LST images. It also implies that excess As plays a decisive role in both images ; as a matter of evidence the two kinds of images clearly differ in the details [33].

The point still in question concerns the specific role of EL2. The influence of the annealing on IRT images is not dramatic [55, 51] ; several authors [73, $75,81,82]$ identified As precipitates distributed along the dislocations. The size of these precipitates varies from 150 to $900 \AA$ and their separation 
between 1 and $10 \mu \mathrm{m}$. This supports the idea that dislocations (which are unaffected) play a key role ; nevertheless it is also observed that annealing strongly enhances the LST image [55] perhaps through a local rearrangement of the scatterers.

At the same time the average density of EL2 centres increases and becomes more uniform across the wafer and this is not consistent with the stability of the IRT image if EL2 is considered as an absorbing site. The only model that could satisfy the various requirements should be :

i) excess As atoms are concentrated along dislocations which act as a diffusion source during annealing.

ii) migrating As atoms give rise to an increasing EL2 density in the bulk essentially because of the increasng antisite $\mathrm{As}_{\mathrm{Ga}}$ density.

iii) the IRT pattern is essentially due to light scattering on decorated dislocations ; this scattering is weakly affected by As migrations.

iv) the LST pattern is enhanced because of a better matching of the size and arrangement of the As droplets with respect to the laser wavelength.

A discussion relative to photo-quenching effects in LST experiments was given by Skolnick [33, 74]. He effectively observed that the scattering image does not change appreciably when colling the sample to $T<100 \mathrm{~K}$; the LST in spite of the fair correlation of the resonance [25]. Temperature is an important parameter in the photo-quenching experiments and further low-temperature data are clearly necessary to determine in what temperature domain photoquenching is observed in the LST measurements.

\section{Photo-cathodo-luminescence.}

Luminescence in GaAs is usually distributed on several bands which are more or less satisfactorily explained [83-86] :

i) close to the gap is the strongest emission $(1.49 \mathrm{eV})$ attributed to donor acceptor or related excitonic transitions $(1.511 \mathrm{eV})$ and also a transition $(1.473 \mathrm{eV})$ attributed to carbon

ii) at lower energy a band at $1.34 \mathrm{eV}$ sometimes appears [83] and should be related to copper

iii) in the infra-red, competitive emissions at 0.8 and $0.65 \mathrm{eV}$ give a broad band with varying maximum.

Actually P/CL emissions are not easy to explain because they depend on several parameters at the same time : absorption coefficient, carrier diffusion, radiative and non radiative recombination yield, concentrations of recombination and killer centres etc... Moreover, the high excitation rate usually required [87] often induce spurious effects such as permanent bleaching [88]. Nevertheless, changing the temperature from $300 \mathrm{~K}$ to $4 \mathrm{~K}$ does not affects dramatically the spectral distributions neither the image even if the total intensity largely increases [83, 89].

The P/CL images are generally recorded by moving the sample under a focussed electron or light beam. A typical system is the Zeiss LSM microscope [90]. The total luminescence macroscopic image agrees fairly well with the wafer scale distribution of EPD, IRT, XRT and resistivity : it shows a $W$ type profile : the brightest zones corresponding to the highest dislocation densities [87, 88, 91, 92] and absorption coefficient at $1.1 \mu \mathrm{m}$.

This distribution is flattened after annealing and also in HB, HGF or In-doped materials [91]. This behaviour follows satisfactorily that of the EL2 ${ }^{+}$ centre [87] in accordance with the EPR experiments. After annealing it was also observed on sample sections [83] that the PL emission is increased near the surface in agreement with the expected out diffusion of EL2.

A correspondance of the P/CL images with other parameters was proposed by Kuma [49]. It was also noted that the P/CL intensity depends on the As content [15] in the same way as EL2. Nevertheless the correlation of P/CL emission with EL2 is not straighforward, especially when looking at a microscopic scale where a cell pattern image is observed. We will discuss this point specifically with each case of emitted wavelength.

4.1 BAND EDGE EMISSION. - The band edge emission at $1.49 \mathrm{eV}$ displays a cell pattern in very good agreement with other images [88] especially IRT ; the cell walls are bright $[56,93]$ and the inner cell space is dark as it can be seen in figures 13-14. The position of the isolated dislocations appears as a dark point in the centre of the clear zone associated to the denuded zone of the Cottrell atmosphere. A more careful microscopic investigation [94] even shows that clusters of dislocations often provide a bright point in the centre of the dark area (Fig. 15). Even within the walls individual dislocations can be selected [90] with high optical resolution systems. The spectral content of these emissions are very similar [94, 95] and the images does not change appreciably with temperature [96], which shows that the same kind of emitters are concerned. Nevertheless the contrast [96] of these images can be very high (a factor 620 was obtained).

In spite of these observations the exact nature of the $\mathrm{C} / \mathrm{PL}$ band edge emission is not easy to understand. The high emission of the walls could be attributed to a higher density of D.A. recombination sites indicated by SIMS analysis [95]. This is in agreement with an observed higher local conductivity but the important contrast of the P/CL image would imply too large a variation in impurity densities [96] even if acceptors different from carbon are taken 


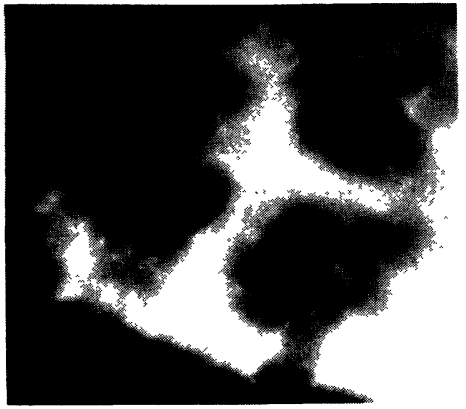

Fig. 13. - P/CL image of the cell structure in the band edge region. (after E. Molva).

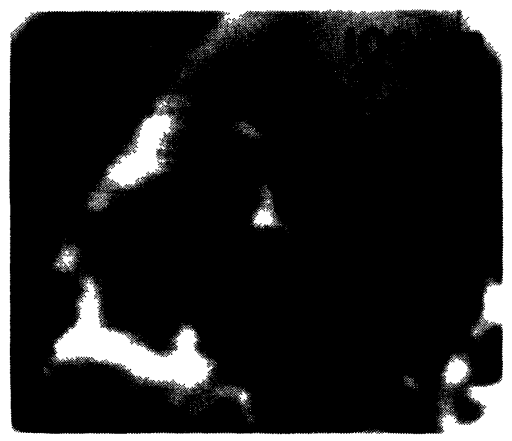

Fig. 14. - P/CL image of the cell structure in the midgap region. (after E. Molva).

into account [49]. A more satisfying explanation should involve the variation [96] of the radiative recombination time $\tau$ : if EL2 is the major recombination centre then the variation of the $\mathrm{EL}_{2}{ }^{+}$compensation (killer) centre density would induce important variation in $\mathrm{P} / \mathrm{CL}$ intensity. Actually the relation of the cell pattern with some species of EL2 centres was verified by Hunter through the usual PQ effect at $20 \mathrm{~K}$. Nevertheless the capture cross section $\left(10^{-18} \mathrm{~cm}^{-2}\right)$ and the densities $\left(10^{16} \mathrm{~cm}^{-3}\right)$ involved do not lead to values of $\tau\left(10^{-5} \mathrm{sec}\right.$. $)$ in agreement with the much shorter lifetime observed $\left(10^{-8} \mathrm{sec}\right.$. $)$.

4.2 INFRA-RED BAND AT $0.8 \mathrm{eV}$. - This extrinsic deep transition is not easily separated from the other infra-red contribution which strongly depends on samples. Nevertheless Watanabe [84] observed that it does not give rise to a pattern of bright cell walls and other workers even evidenced an anti-correlation $[49,96,97]$ with the band edge images (Fig. 15) : the emitted intensity decreases in the high EPD regions giving a complementary $\mathbf{M}$ profile [97] and the cell walls are dark thus fitting with a distribution of killer centres. It is generally supposed that a deep donor $[84,86]$ is involved in this radiative transition which could be responsible for the non radiative capture of electrons giving rise [96] to the lifetime $\tau$. Possible origins could be $\mathrm{V}_{\mathrm{Ga}}$ [86] or $\mathrm{EL}^{+}{ }^{+}[56,85,97]$. This emission is excited by Argon a)

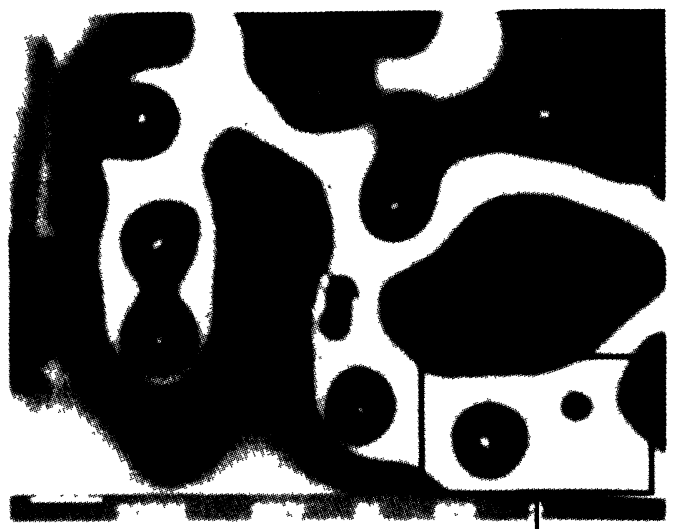

CATHODOLUMINESCENCE b)

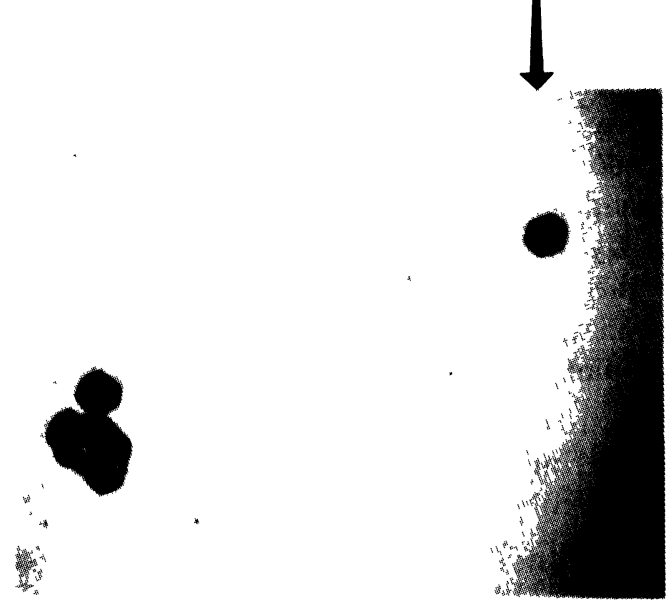

\section{NOMARSKI}

Fig. 15. - Microscopic view of the luminescence (a) in the region of dislocations (b) (after A. Hunter).

light but not by YAG wavelength and these images do not quench at low temperature. After annealing, this inverted pattern is strongly reduced and becomes undiscernible (49).

4.3 INFRA-RED BAND AT $0.65 \mathrm{eV}$. - This emission is competitive with the $0.8 \mathrm{eV}$ radiation and disappears completely in doped materials [97]; a wavelength of $1.32 \mu \mathrm{m}(0.94 \mathrm{eV})$ selectively excites this transition. The corresponding images are of the same kind as the band edge ones and correlate with high absorption ; Tajima supposed [97] that absorption and emission are related to the same centre but Samuelson [98] disagrees; the reinforced emission from the walls agrees with an EL2 contribution [85, 86] ; other arguments for EL2 involvement are the quenching of the image [86,97], its relation to the excess of arsenic and also the sensitivity to the $1.06 \mu \mathrm{m}$ excitation. The role of oxygen proposed by $\mathrm{Yu}[99]$ is no longer considered.

\section{Conclusion.}

The EL2 centre is probably not a unique defect and it displays a variable DLTS signature $[6,100]$; the 
a)

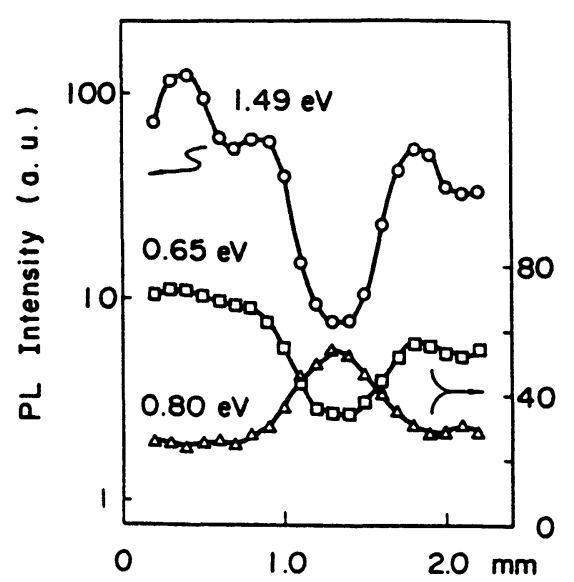

b)

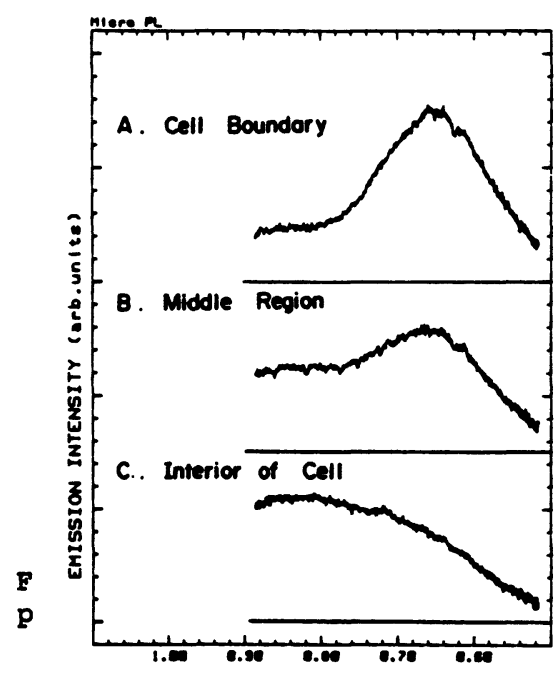

Fig. 16. - PL profiles of emission (a) at 1.49-0.8-0.65 eV and spectral dependence (b). (after M. Tajima). microscopic configurations are not definitely established and the key feature is the photo-quenching property. But this variable structure leads also to imagine that the thermal regeneration temperature $T_{\mathrm{m}}$ which a quencing parameter, should also be variable ; actually the optical, electrical or EPR detection of thresholds shows several different temperatures : $60,125,250,350 \mathrm{~K}$; the most important being at $125 \mathrm{~K}$. Their relative importance largely depends on samples and experiments. So it is not surprising that the conclusions induced by image analysis are also multiple and diversified, at the moment.

An important point is that there are two scales of investigations: the macroscopic one which agrees with a rather homogeneous distribution of defects which can be photo-quenched and regenerate above $125 \mathrm{~K}$ (they will be called standard $\mathrm{EL}^{+}$and a microscale pattern directly controlled by the dislocation structure ; it is not definitely established if these dislocations generate or getter EL2 or, more likely, if there are not correlated with EL2 or if several kinds of «EL2 » are involved. As a matter of fact the scattering of light on the decorated dislocations must not be ignored by the LST resonance at $1.1 \mu \mathrm{m}$ is still unexplained. The $\mathrm{P} / \mathrm{CL}$ emission image is a complex information where the role of $\mathrm{EL}^{0}{ }^{0}$ with respect to $\mathrm{EL} 2^{+}$has to be clarified.

The mechanism of thermal regeneration of the quenched EL2 centres has to be more carefuly analysed and explained in order to separate the possible different species of this very complex and puzzling centre; no doubt the infra-red imaging [101] will be a powerful means of obtaining a better insight in this field.

\section{References}

[1] DRIP I Symp. Montpellier 1985, Proceedings, Ed. J. P. Fillard (Elsevier) MS monographs 31 (1985).

[2] DRIP II Symposium. Proceedings, Ed. E. Weber (Elsevier) MS monographs 44 (1987).

[3] Vignaud, D. and Farvacoue, J. F., Solid. State Commun. 60 (1986) 527.

[4] Fillard, J. P., Bonnafe, J. and Castagne, M., Appl. Phys. A 149 (1984) 35.

[5] Fillard, J. P., Bonnafe, J. and Castagne, M., Solid. State Commun. 52 (1984) 855.

[6] TANiguchi, M., MochizuKI, Y. and IKoma, T., Semi-Ins. III-V Mat. Conf. Kah-nee-ta, Eds. D. C. Look and J. S. Blakemore, Shiva (1984) p. 231.

[7] Omling, P., Weber, E. R., Samuelson, L., Phys. Rev. B. 335 (1986) 880.

[8] Weber, E. R., Solid State Commun. 60 (1986) 871.

[9] Hunter, A. T., DRIPP II Symposium, (Elsevier), MS Monographs 44 (1987) 137.
[10] Ozawa, S., Miyairi, M., Nakajima, N. and Fukuda, T., Inst. Phys. Conf. Karuizawa 79 (1985) 25.

[11] Kuwamoto, H., Holmes, D. E., DRIPP II Symposium. (Elsevier) MS Monographs 44 (1987) 15.

[12] Mircea, A. and Bois, D., Inst. Phys. Conf. 46 (1978) 82.

[13] Martin, G. M., Appl. Phys. Lett. 39 (1981) 747.

[14] Yahata, A., Sato, T., Kikuta, T. and IshidA, K., M.R.S. Symp. (San Francisco) 46 (1985) 179.

[15] Tajima, M., Yamata, A., Kikuta, T., Tsukada, N. and IshidA, K., Semi. Ins. III-V Mat. Conf. (Hakone), Eds. M. Kukimoto and S. Miyazawa (OHM and North Holland) 1986, p. 305.

[16] Vincent, G., Bois, D. and Chantre, A., J. Appl. Phys. 53 (1982) 3643.

[17] Van Vechten, J. A., M.R.S. Symp. San Francisco 46 (1985) 83. 
[18] Martin, G. M. and Makram-Ebeid, S., Deep Levels in Semicon, Ed. Pantelides (1983).

[19] Tajima, M., Jpn. J. Appl. Phys. 21 (1982) L 227.

[20] Dobrilla, P. and Blakemore, J. S., DRIP I Symp. 127, Proc. (1985).

[21] TsukadA, N., KikutA, T. and IshidA, K., Jpn. J. Appl. Phys. 24 (1985) L 302.

[22] IshidA, K., YamatA, A. and KikutA, T., Jpn. J. Appl. Phys. 24 (1985) L 250.

[23] Castagne, M., Fillard, J. P. and Bonnafe, J., Solid. State Commun. 54 (1985) 653.

[24] Castagne, M., Bonnafe, J., Asgarinia, M. and FILLARD, J. P., unpublished.

[25] Ogawa, T. and KoJima, T., DRIP II Symposium (Elsevier) MS Monograph 44 (1987) 207.

[26] Brozel, M. R., DRIP II Symposium (Elsevier) MS Monograph 44 (1987) 225.

[27] Tsukada, N., Kikuta, T. and Ishida, K., Jpn. J. Appl. Phys. 24 (1985) L 302.

[28] Fuchs, F., Dischler, B. and Kaufmann, U., Semi. Ins. III-V Mat. Conf. (Hakone) (1986) 329.

[29] Fillard, J. P., Bonnafe, J. and Castagne, M., Phys. State Sol. 72 (1982) K 65.

[30] Bonnafe, J., de Murcia, M., Castagne, M. and Fillard, J. P., Phys. State Sol. 76 (1983) K 147.

[31] Levinson, M., Phys. Rev. B 28 (1983) 3660.

[32] Skolnick, M. S., Hope, D. A. O. and CockAyne, B., Semi-Ins. III-V Conf. Kah-nee-ta 446 (1984).

[33] Skolnick, M. S., Brozel, M. R., PitT, A. D. and Maguire, J., Semi-Ins. III-V Mat. Conf. Ed. H. Kukimoto (Hakone) 139 (1985).

[34] Castagne, M., Fillard, J. P., Bonnafe, J. and Gall, P. Def. Semi-Con. Ed. H. J. Von Bardeleben 1 (1986) 371.

[35] Fillard, J. P., Montgomery, P., Gall, P. and Asgarinia, A. and Bonnafe, J., Jpn. J. Appl. Phys. (to appear 1987).

[36] Bray, R., Solid State Commun. 60 (1986) 867.

[37] Dobrilla, P. and Blakemore, J. S., J. Appl. Phys. 61 (1987) 1442.

[38] Brozel, M. R., Grant, L., Ware, R. M. and Stirland, D. J., Appl. Phys. Lett. 42 (1983) 610.

[39] Kaufmann, U., Windscheif, J., Bamler, M., SCHNEIDER, J. and KoHL, F., Semi-Ins. III-V Mat. Conf. Kah-nee-ta (1984), Eds. D. C. Look, J. S. Blakemore, Shiva (1984) p. 246.

[40] Silverberg, P., Nielsen, L., OMling, P. and SAMUElson, L., DRIP I Symposium (Elsevier) MS Monographs 31 (1985) 157.

[41] Windscheif, J., Baemler, M., KaufmanN, U., DRIP I Symposium (Elsevier) MS Monographs 31 (1985) 193.

[42] Dobrilla, P., Blakemore, J. S. and Koyama, R. Y., Semi-Ins. III-V Mat. Conf. Kah-nee-ta, Eds. D. C. Look, J. S. Blakemore, Shiva (1984) p. 282.

[43] BonNeT, M., DRIP I Symposium (Elsevier) MS Monographs 31 (1985) 103.

[44] Silverberg, P., Omling, P. and Samuelson, L., DRIP II Symposium (Elsevier) MS Monographs 44 (1987) 281.
[45] Sargent, L., Dobrilla, P., Tang, R. S. and BlaKemore, J.S., DRIP II Symposium (Elsevier) MS Monographs 44 (1981) 55.

[46] Jordan, A. S., Caruso, R. and Von Neida, A. R., Bell. Syst. Tech. J. 59 (1980) 593.

[47] Holmes, D. E., Chen, R. T., Elliott, K. R. and KirkPatrick, C. G., Appl. Phys. Lett. 40 (1982) 46.

[48] Keinemann, M., Meyer, B. K. and Spaeth, J. M., DRIP II Symposium (Elsevier) MS Monograph 44 (1987) 289.

[49] Kuma, S. and OtокI, Y., DRIP II Symposium (Elsevier) MS Monographs 44 (1987) 1.

[50] Gray, M. L. and GRIM, K. A., DRIP II Symposium (Elsevier) MS Monographs 44 (1987) 25.

[51] Skolinick, M. S., Reed, L. J. and PitT, A. D., Appl. Phys. Lett. 44 (1984) 447.

[52] Alt, H. Ch. and Packeiser, G., J. Appl. Phys. 60 (1986) 2954.

[53] Brozel, M. R. and Skolnick, M. S., Semi-Ins. IIIV Mat. Conf. (Hakone) Eds. H. Kukimoto and S. Miyazawa (OHM and North Holland) 1986, p. 109.

[54] Martin, S., Duseaux, M., DRIP I Symposium (Elsevier) MS Monographs 31 (1985) 287.

[55] Otoki, Y., Nakamori, M., Nakazono, R. and KumA, S. Semi-Ins. III-V Mat. Ed. H. Kukimoto (Hakone) (1985) p. 285.

[56] Dussac, M., Dupuy, M. and Molva, E., DRIP I Symposium (Elsevier) MS Monographs 31 (1985) 209.

[57] Gall, P., Castagne, M., Fillard, J. P. and BonNAFE, J. DRIP II Symposium (Elsevier) MS Monographs 44 (1987) 215.

[58] Wang Li, Thesis Montpellier (1986) unpublished.

[59] Brozel, M. R., Foulkes, E. J. and StiRland, D. J., GaAs and Rel. Comp. Inst. Phys. Conf. Biarritz 74 (1984) 59.

[60] Système d'Analyse de Topographie de Transmission Infra-rouge (SATTIR) - SIEG - 3000 (Nîmes) France.

[61] Fillard, J. P., DRIP II Symposium (Elsevier) MS Monographs 44 (1987) 185.

[62] StiRland, D. J. and Brozel, M. R., MRS Symp. Proc. San Francisco 46 (1985) 213.

[63] Clark, S., Brozel, M. R. and Stirland, D. J., DRIP I Symposium (Elsevier) MS Monographs 31 (1985) 201.

[64] Brozel, M. R., Clark, S., Stirland, D. J., Semi-Ins. III-V Mat. Conf. Ed. H. Kukimoto, Hakone (1985) p. 133.

[65] Katsumata, T. and Fukuda, F., Rev. Sci. Inst. 57 (1986) 202.

[66] Dobrilla, P. and Blakemore, J. S., J. Appl. Phys. 60 (1986) 169.

[67] Nanishi, Y., Miyazawa, S. and Matsuoka, Y. DRIP I Symposium (Elsevier) MS Monographs 31 (1985) 225.

[68] Lee, R. E., Hunter, A. T., Bryan, R. P. and OlSEN, H. M., GaAs IC Symp. Malibu (1985).

[69] Dobrilla, P., DRIP II Symposium (Elsevier) MS Monographs 44 (1987) 305.

[70] Sкоlnick, M. S., DRIP I Symposium (Elsevier) MS Monographs 31 (1985) 165. 
[71] Lagowski, J. and Gatos, J. C., 13th Int. Conf. on Defect in S/C Coronado (1984).

[72] Packeiser, G., NATO Workshop Oxford (April 1987).

[73] Stirland, D. J., Kitching, S., Hart, D. G., Giddings, T. M. and Hughes, A. J., NATO Workshop Oxford (April 1987).

[74] Skolnick, M. S. and Brozel, M. R., Appl. Phys. Lett. 48 (1986) 341.

[75] Fillard, J. P., Bonnafe, J. and Castagne, M., J. Appl. Phys. 56 (1984) 3020.

[76] Moriya, K. and Ogawa, T., Jpn. J. Appl. Phys. 22 (1983) L 207.

[77] Moriya, K., Appl. Phys. Jpn. 55 (1986) 542.

[78] DuseauX, M., Nato Workshop Oxford (April 1987).

[79] Fillard, J. P., Wang, L., Zhang, F., Gall, P. and Castagne, M., Semi. Con. Sci. Tech., to appear.

[80] Ogawa, T., Jpn. J. Appl. Phys. 25 (1986) L 316.

[81] Wettling, W. and Windscheif, J., Appl. Phys. Lett. 40 (1986) 191.

[82] Walukiewicz, W., Bourret, E., Yau, W. F., Murray, R. E. and Haller, E. E. Jr., DRIP II Symposium (Elsevier) MS Monographs 44 (1987) 297.

[83] Kimura, H., Hunter, A. T., Olsen, H. M., Inst. Phys. Conf. Ser. 79 (1985) 1.

[84] Watanabe, K., Nakanishi, H., Yamada, K. and Hoshikawa, K., Appl. Phys. Lett. 45 (1984) 643.

[85] Kikuta, T., Terashima, K. and Ishida, K., Jpn. J. Appl. Phys. 22 (1983) L 409.
[86] Kikuta, T., Katsumata, T., Obokata, T. and Ishida, K., Inst. Phys. Conf. Ser. 79 (1985) 47.

[87] Wettling, W. and Windscheif, J., Appl. Phys. Lett. 40 (1986) 191.

[88] Windscheif, J. and Wettling, W., Symp. on GaAs Rel. Comp. Las Vegas (1986).

[89] Chin, A. K., CAmlibel, I., CARUSo, R., Young, MSS. and Von NeIDA, AR. Jour. Appl. Phys. 57 (1985) 2203.

[90] Marek, J., Elliot, A. G., Wilke, V. and Geiss, R., Appl. Phys. Lett. 49 (1986) 1732.

[91] Hovel, H. J. and Guidotti, D., I.E.E.E. Trans. 32 (1985) 2331.

[92] Wettling, W. and Windscheif, J., Nato Workshop Oxford (April 1987).

[93] Chin, A. K., CARuso, R., MSS YOUNG, AR VON NEIDA, Appl. Phys. Lett. 45 (1984) 552.

[94] Hunter, A. T., Kimura, H., Molsen, H. and Winston, HV., J. Elect. Mat. 15 (1986) 215.

[95] Bunod, P., Molva, E., Chabli, A., Bertin, F., Bletry, J. and LE Si DANG, Def. in SemiCond. Ed. H. J. Von Bardeleben (1986) 1229.

[96] Hunter, A. T., Appl. Phys. Lett. 47 (1985) 715.

[97] Tajima, M., Semi Ins. III-V Mat. Conf. Ed. H. Kukimoto (1985) 305.

[98] Samuelson, L. and Omling, P., Phys. Rev. B 34 (1986) 5603.

[99] Yu, P. W., Walters, D. C. and Mitchel, W. C., Jour. Appl. Phys. 60 (1986) 3864.

[100] Wagner, J. F. and Van Vechten, J. A., Phys. Rev. B 35 (1987) 2330.

[101] Fillard, J. P., To be published in Ann. Télécommun. (1987) 